\title{
Advanced Manufacturing Process of Orthotic Shoe Insoles Using A New Material Based on the Taguchi Methodology
}

\author{
Abet Adhy Anthony ${ }^{1}$ Paulus Wisnu Anggoro ${ }^{2, *}$ Jamari $^{1}$ Athanasius Priharyoto
}

Bayuseno $^{1}$

\author{
${ }^{1}$ Department of Mechanical Engineering, University of Diponegoro, Jl. Prof. Soedarto, SH., Tembalang, Semarang \\ 50275, Central Java, Indonesia. \\ ${ }^{2}$ Department of Industrial Engineering, Faculty of Industrial Technology, University of Atma Jaya Yogyakarta, Jl \\ Babarsari No. 44, Sleman, Yogyakarta 55281, Indonesia \\ *Corresponding author. Email: p.wisnuanggoro@gmail.com
}

\begin{abstract}
Some people who have foot deformities such as diabetes often experience pain and difficulty wearing shoes. The optimization of advanced manufacturing based on CAM - CNC with EVA rubber foam material has not been optimal. Two new materials are proposed in this paper for manufacturing optimization through the experimental stage. Some people who have foot deformities such as diabetes often experience pain and difficulty wearing shoes. The optimization of advanced manufacturing based on CAM - CNC with EVA rubber foam material has not been optimal. Two new materials are proposed in this paper for manufacturing optimization through the experimental stage. Some people who have foot deformities such as diabetes often experience pain and difficulty wearing shoes. The optimization of advanced manufacturing based on CAM - CNC with EVA rubber foam material has not been optimal. Two new materials are proposed in this paper for manufacturing optimization through the experimental stage. The two new materials proposed in this paper provide very significant results when compared with EVA rubber Foam. This new material can reduce the time needed to work on one pair of insoles to 6.0 hours / pair ( $75 \%$ faster) with an average surface smoothness of $7.54 \mu \mathrm{m}$. The output of this research has significant implications for researchers and the manufacturing industry in the field of the shoe design; optimization of shoe manufacturing on CAM and CNC maching. This research also has implications for the use of modern computer-aided reverse engineering systems.
\end{abstract}

Keywords: Foot Deformity, New Material Insole, CAM, Taguchi Method.

\section{INTRODUCTION}

The legs are members of the human body that play a role in helping humans do almost all the activities carried out. The legs are part of the limbs that serve as a buffer for the body when performing activities. [1] in a journal paper states that the geometry of the human foot is very complex (consisting of twenty-six bones, thirty-three joints, one hundred and seven ligaments, and nineteen muscles) and different. Therefore, the foot requires a pedestal in the form of different shoes - different shapes, so as to be able to protect and provide comfort for users in doing their activities. The insole is the inside of the shoe. This part is made of rubber, foam, or plastic. Curveshaped insole that follows the flat shape of the soles of human feet. Rubber insole has good elasticity when compared to other materials used for people who have deformity of the feet.

Some people have abnormal foot shape as usual. This deformity of the foot is often referred to as foot deformities, such as: pronation, flat feet, neuroma, plantar fasciitis, arch pain, metatarsalgia, and diabetes. This is related to the distribution of press on the soles of abnormal feet, thus causing the feet to often feel pain. Foot deformities can also be caused by the use of shoes with inner footwear that do not correspond to the shape of the feet. Therefore, people with foot deformities require a special insole design, or better known as orthotic footwear (insole). 
However, until now there is still rarely found in-depth research on the material of special footwear that is appropriate for people with foot deformities. However, research on manufacturing optimization on Ethylene Vinyl Acetate (EVA) rubber material with CNC machines as reported by $[2,3,4]$ explained that EVA rubber insole with material can be done very well and has a surface smoothness of less than $8 \mu \mathrm{m}$. Insole work using CNC Rolland Modela MDX milling machines. The results of research in this study in the form of two strategy (toolpath strategy) optimal for working eva rubber material on the shape of normal human feet. Both strategies are raster finishing and step and shallow.

Ethylene Vinyl Acetate (EVA) rubber foam is a lightweight rubber material that has good elasticity and is very safe against shock loads that may arise. EVA rubber foam is one of the types of rubber that is most often used in the manufacture of insole and outsole [5]. This material has the best characteristics among other materials if used for the manufacture of insole shoes on the feet of the average human generally. The medical field also often uses this material to make orthotic footwear for people with foot deformities.

$[2,3,4,6,7]$ in research that has been reported successfully obtained a pair of insole products for diabetics (iso_diabetes) with a high-risk scale [8]. This product is done with optimal cutting parameter conditions on CNC Roland Modela MDX - 40R machines. The result of this book nation is completely in accordance with the shape of the contour of the patient's feet. However, the reported results are still not able to be said to be maximal, because the characteristics of eva rubber materials used still produce a long working time ranging from 10-12 hours per pair of shoes, surface roughness is still above $8 \mu \mathrm{m}$, machining process capability of EVA rubber material is quite complicated so there needs to be more research on new EVA rubber material proposed by orthotic laboratory. PT Rehabilitation Center Jakarta. This material is very suitable to be used as an insole material but can't be done tensile test process. The hardness of this material ranges from 40 - 55 HRC. Therefore, it is necessary to conduct further research on optimization of orthotic shoe insole manufacturing using two new materials used in this paper.

Computer Aided Design (CAD) is one of the technology developments in the field of product design that is considered as a solution to the problem because it is able to reduce the time of insole design and reduce the cost of making orthotic footwear according to research conducted by [9]. The fast, precise, and accurate insole manufacturing process can use the Computer Aided Reverse Engineering System (CARE System) in the application of iso product design specifically for diabetic patients [2, 3, 4, 7]. Research on orthotic shoe insole manufacturing in diabetic patients integrated with modern technology is carried out by scanning the patient's feet with a 3D scanner Handy Scan 700TM and processed using reverse engineering with $\mathrm{CAD}$ technology, while the manufacturing process uses Aditive Manufacturing technology on 3D Ogden 350V (Cogent Engineering) machines. A variety of iso_diabetes successfully obtained $[2,3,4,6,7]$ through the manufacturing optimization process in order to obtain an optimal design in accordance with the shape and contour of the patient's foot surface.

Surface roughness is critical to product quality and its function in the manufacturing industry. Minimal surface hardness is important because of increased consumer demand for quality, cheaper products, minimum friction, maximum lubrication, and minimum wear. This will also affect manufacturing and production costs. The process of modeling and optimization is very important in the manufacture of a product. The manufacturing process is characterized by many dynamically interacting process variables [10]. Modeling surface roughness is difficult because it is influenced by various variables. Recently many surface roughness modeling systems, simulations, optimizations are designed using different cutting parameters. [11] investigated new methods for determining the objectives of optimal cutting conditions and mathematical models for surface roughness (Ra) in CNC affected by feeding speed, stepover, and dip depth (dept of cut).

Taguchi is a method that includes an experimental plan with the aim of obtaining data by conducting controlled experiments and analyzing data to obtain information about the behavior and processes provided $[12,13]$. [14] used Taguchi method to determine optimal parameters on CNC End Milling on AL 7075 aluminum alloy. The parameters in question are four, namely spindle speed, feedrate, depth of cut (doc), and cutter milling type provides optimal surface roughness response. [15] revised experiments on researching the interaction between material removal rate and surface roughness with appropriate parameters such as feedrate, depth of cut (doc), and spindle speed in milling machines using ANOVA. [16] predicted the influence of parameters namely spindle speed, deep of cut, feedrate and diameter size of the tool on the roughness of the surface of the milling machine with experimental design. [17] used experimental design methods to predict the Expansion Ratio of EVA foam material and used Finite Element Simulation to estimate Shoe Expansion Shape. [18] examined the selection of optimal ordering parameters such as spindle speed, depth of cut (doc), and feedrate for advance workmanship in milling process in the calculation of surface roughness and maximizing material removal rate.

To obtain the results of such manufacturing optimization, an orthogonal array L18 6x34 is assigned according to the Taguchi method set out in this study. The 
response taken to get a significant relationship of optimal cutting parameters is roughness surface and this is in accordance with research that has been done by several researchers: $[19,20]$. But the researchers all used only non rubber materials except $[6,21]$. To see the optimal parameter value is used taguchi method. Machinability analysis is seen and determined based on the actual work time using a stopwatch measuring instrument.

This paper aims to obtain optimal cutting parameter conditions and significant influence between cutting parameters on the quality of machining results on the two new materials proposed. The problem discussed is about the value of surface roughness $(\mathrm{Ra})$ in EVA rubber foam material proposed by PT. Jakarta Rehabilitation Center as a new material that will be used in the next insole manufacturing process. Two types of EVA rubber foam are determined as materials that will be in the manufacturing process into insole. One material is the material that was manufactured in this study, while the other material will be taken data from the research of [6]. Based on the measurement of violence that had been done, in the task research finally explained that the material proposed by PT. Jakarta Rehabilitation Center has a violent value ranging from $60-70 \mathrm{HRc}$, but this material can't be done tensile test process to determine the value of stress and streghtnya. This research will later analyze and compare from Ra and Machinability of the two materials.

\section{METHOD}

One diabetes mellitus patient with a high risk factor (see Figure 1.a. is determined as the object of research and scanning process with Handy Scan 700TM tool (see Figure 1.b.) until external output is obtained in the form of a picture of the patient's foot in cloud mesh format (see Figure 1.c.). This image after being fixed by CAD verification software is then done reverse engineering (RE) process with CAD PowerSHAPE 2017 until the desired insole design image is obtained (see Figure 1.d.).

The curve base surface modeling (CBS-Modeling) method is used to design the insole as presented in Figure 2. The CBS-Modelling designed 3D insole is then employed using the new material presented in Figure 3. Five parameters of buyers are set out in this study, namely: material type (A); spindle speed (B); step over (C); feed rate (D) and toolpath strategy of the buyer (E) as the predictor parameter (independent variable) which each consists of 3 levels (see Table 1). The response variables measured in this paper are two, namely: surface roughness and insole working time in $\mathrm{CNC}$ machines. The response was obtained by measuring the roughness value of the insole surface on the designated part with the Mark Surf PS1 surface roughness tester. Insole working time is measured using a stopwatch measuring instrument. Lay out the experimental design in this paper using the $\mathrm{L}_{27} 3^{5}$ orthogonal array and presented in Table 2.

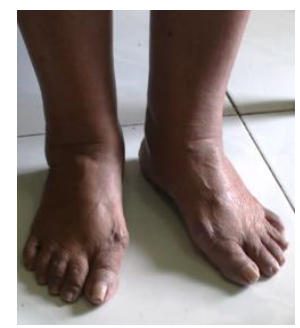

(a)

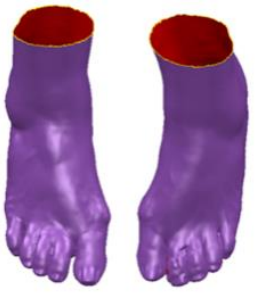

(c)

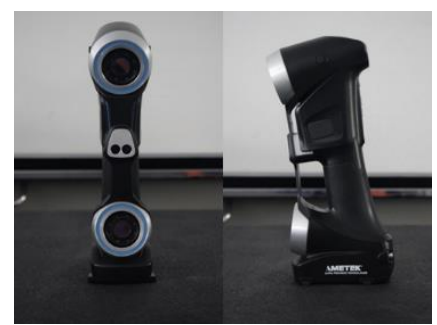

(b)

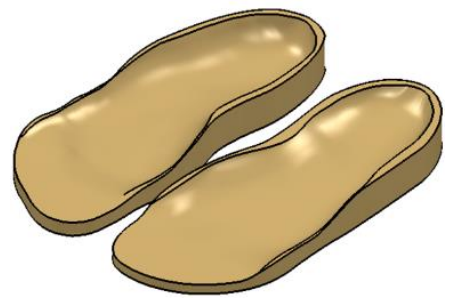

(d)
Figure 1 Research objects; (a) diabetic patients; (b) scanning tools; (c) 3D mesh CAD fit foot model; (d) 3D CAD optimal insole model

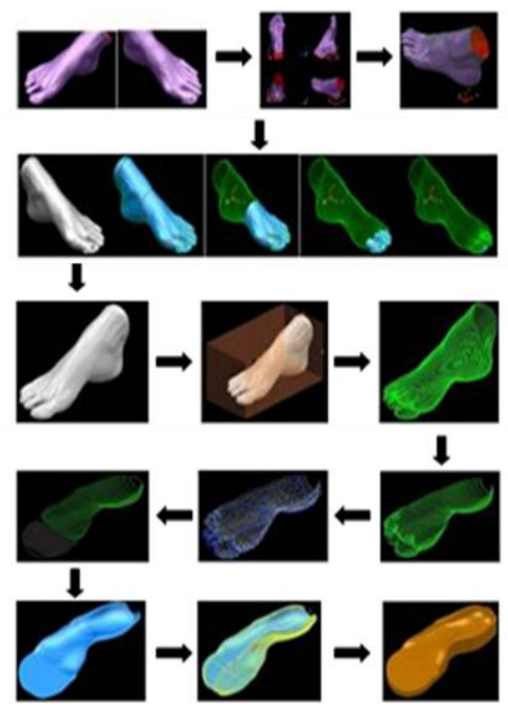

Figure 2 CBS - modeling insole shoes orthotic [6]

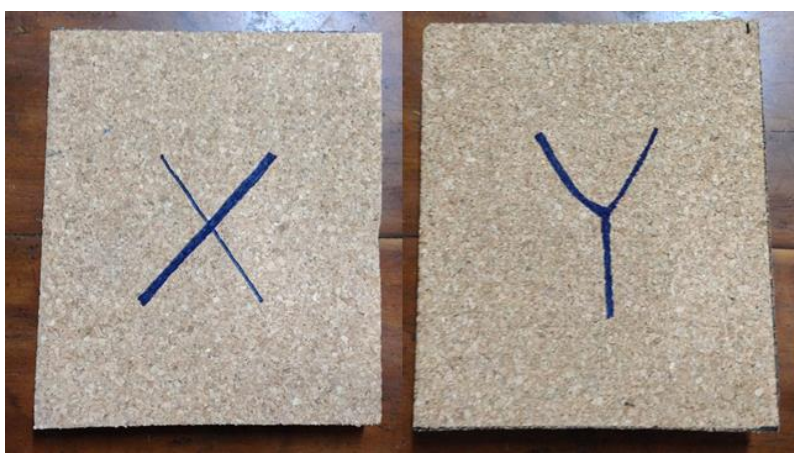

Figure 3 New material $\mathrm{X}$ and $\mathrm{Y}$ 
Table 1. Cutting Parameter Condition

\begin{tabular}{llll} 
& \multicolumn{2}{c}{ Level } & \\
& $\mathbf{1}$ & $\mathbf{2}$ & $\mathbf{3}$ \\
\hline (A) Type of Material & $\mathrm{X}$ & $\mathrm{Y}$ & EVA Foam \\
(B) Spindle Speed & 13000 & 14000 & 15000 \\
(C) Stepover & 0.15 & 0.2 & 0.25 \\
(D) Feedrate & 800 & 850 & 900 \\
(E) Toolpath & Raster & Raster 45 & Raster 90 \\
\hline
\end{tabular}

Table 2. Orthogonal array L2735 experiment on new material EVA foam rubber

\begin{tabular}{|c|c|c|c|c|c|c|c|c|c|}
\hline $\exp$ & $\mathbf{A}$ & B & C & D & $\mathbf{E}$ & $\begin{array}{c}\text { Ra } \\
\text { Left Insole } \\
\qquad \mu \mathrm{m} \\
\end{array}$ & $\begin{array}{r}\text { Ra } \\
\text { Right } \\
\text { Insole } \\
\mu \mathrm{m}\end{array}$ & $\begin{array}{c}\text { TM } \\
\text { Left Insole } \\
\text { Minutes }\end{array}$ & $\begin{array}{c}\text { TM } \\
\text { Right Insole } \\
\text { Minutes } \\
\end{array}$ \\
\hline 1 & 1 & 1 & 1 & 1 & 1 & 8,265 & 8,513 & 415,62 & 421,854 \\
\hline 2 & 1 & 1 & 1 & 1 & 2 & 7,315 & 7,534 & 322,39 & 327,226 \\
\hline 3 & 1 & 1 & 1 & 1 & 3 & 7,889 & 8,126 & 254,10 & 257,912 \\
\hline 4 & 1 & 2 & 2 & 2 & 1 & 7,810 & 8,044 & 427,70 & 434,116 \\
\hline 5 & 1 & 2 & 2 & 2 & 2 & 7,784 & 8,018 & 313,83 & 318,537 \\
\hline 6 & 1 & 2 & 2 & 2 & 3 & 7,589 & 7,817 & 254,29 & 258,104 \\
\hline 7 & 1 & 3 & 3 & 3 & 1 & 7,461 & 7,685 & 395,29 & 401,219 \\
\hline 8 & 1 & 3 & 3 & 3 & 2 & 7,514 & 7,739 & 308,32 & 312,945 \\
\hline 9 & 1 & 3 & 3 & 3 & 3 & 7,431 & 7,654 & 277,14 & 281,297 \\
\hline 10 & 2 & 1 & 2 & 3 & 1 & 7,479 & 7,703 & 438,42 & 444,996 \\
\hline 11 & 2 & 1 & 2 & 3 & 2 & 7,767 & 8,000 & 390,37 & 396,226 \\
\hline 12 & 2 & 1 & 2 & 3 & 3 & 7,568 & 7,795 & 333,09 & 338,086 \\
\hline 13 & 2 & 2 & 3 & 1 & 1 & 7,315 & 7,534 & 456,49 & 463,337 \\
\hline 14 & 2 & 2 & 3 & 1 & 2 & 7,823 & 8,058 & 361,57 & 366,994 \\
\hline 15 & 2 & 2 & 3 & 1 & 3 & 7,564 & 7,791 & 345,72 & 350,906 \\
\hline 16 & 2 & 3 & 1 & 2 & 1 & 8,142 & 8,386 & 449,17 & 455,908 \\
\hline 17 & 2 & 3 & 1 & 2 & 2 & 7,878 & 8,114 & 390,34 & 396,195 \\
\hline 18 & 2 & 3 & 1 & 2 & 3 & 8,456 & 8,710 & 326,39 & 331,286 \\
\hline 19 & 3 & 1 & 3 & 2 & 1 & 6,984 & 7,194 & 420,02 & 426,320 \\
\hline 20 & 3 & 1 & 3 & 2 & 2 & 7,102 & 7,315 & 385,56 & 391,343 \\
\hline 21 & 3 & 1 & 3 & 2 & 3 & 6,989 & 7,199 & 395,88 & 401,818 \\
\hline 22 & 3 & 2 & 1 & 3 & 1 & 6,458 & 6,652 & 480,74 & 487,951 \\
\hline 23 & 3 & 2 & 1 & 3 & 2 & 6,597 & 6,795 & 398,55 & 404,528 \\
\hline 24 & 3 & 2 & 1 & 3 & 3 & 6,998 & 7,208 & 347,14 & 352,347 \\
\hline 25 & 3 & 3 & 2 & 1 & 1 & 7,012 & 7,222 & 400,05 & 406,051 \\
\hline 26 & 3 & 3 & 2 & 1 & 2 & 6,458 & 6,652 & 325,19 & 330,068 \\
\hline 27 & 3 & 3 & 2 & 1 & 3 & 6,782 & 6,985 & 380,07 & 385,771 \\
\hline
\end{tabular}

A detailed description of experiments conducted by researchers from the scanning stage to obtaining optimal cutting conditions from the optimization process of orthotic shoe insole manufacturing insole in diabetic patients can be presented in Figure 3. 


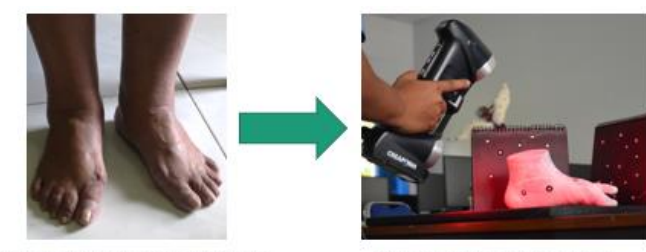

Diabetic patient foot
Scanning Process

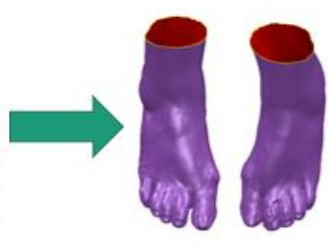

3D Mesh of foot

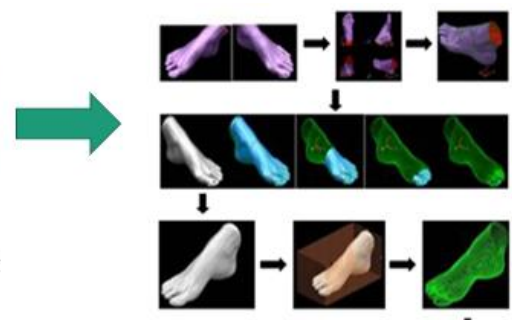

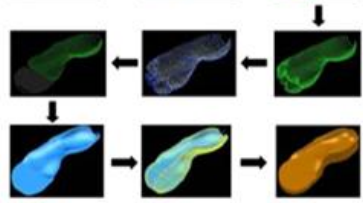

CBS Modelling

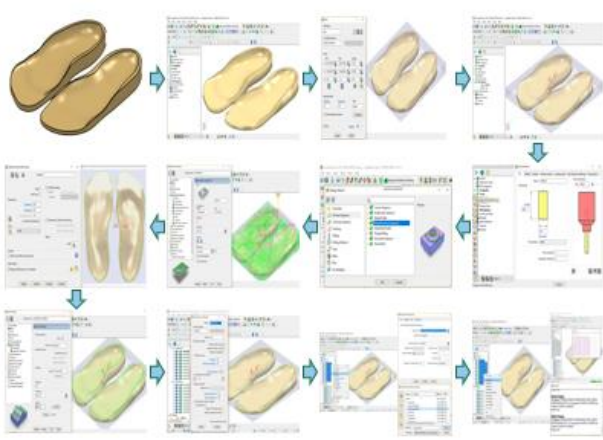

CAM Process for CNC Milling with PowerMill 2019

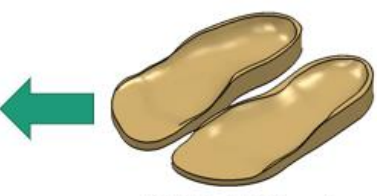

3D Solid Insole

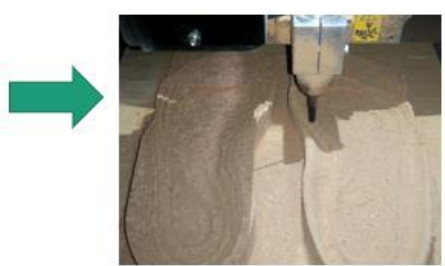

Machining Process Insole

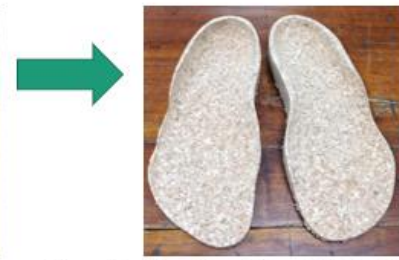

Insole Product for Diabetic Patient

Figure 3 Research flowchart methodology

The response value in Table 2, then processed using Minitab 2018 software with characters of "smaller the

Table 3. Surface roughness 1 result better" quality will be obtained some of the outsides presented in Table 3 to Table 6 and Figure 4 to Figure 7.

\begin{tabular}{|c|c|c|c|c|c|c|}
\hline & \multirow{2}{*}{ Control factor } & \multicolumn{5}{|c|}{ Surface roughness Ra 1} \\
\hline & & Level 1 & Level 2 & Level 3 & Delta & Rank \\
\hline \multicolumn{7}{|c|}{$\mathrm{S} / \mathrm{N}$ ratio $(\mathrm{dB})$} \\
\hline (A) & Type of Material & $-17,69$ & $-17,81$ & $-16,67$ & 1,14 & 1 \\
\hline (B) & Spindle Speed & $-17,47$ & $-17,28$ & $-17,43$ & 0,19 & 4 \\
\hline (C) & Step over & $-17,53$ & $-17,32$ & $-17,32$ & 0,21 & 3 \\
\hline (D) & Feedrate & $-17,34$ & $-17,64$ & $-17,19$ & 0,45 & 2 \\
\hline (E) & Toolpath & $-17,40$ & $-17,32$ & $-17,45$ & 0,14 & 5 \\
\hline \multicolumn{7}{|c|}{ Means $(\mu \mathrm{m})$} \\
\hline (A) & Type of Material & 7,673 & 7,777 & 6,820 & 0,957 & 1 \\
\hline (B) & Spindle Speed & 7,484 & 7,326 & 7,459 & 0,158 & 4 \\
\hline (C) & Step over & 7,555 & 7,361 & 7,354 & 0,202 & 3 \\
\hline (D) & Feedrate & 7,380 & 7,637 & 7,253 & 0,385 & 2 \\
\hline (E) & Toolpath & 7,436 & 7,360 & 7,474 & 0,114 & 5 \\
\hline
\end{tabular}

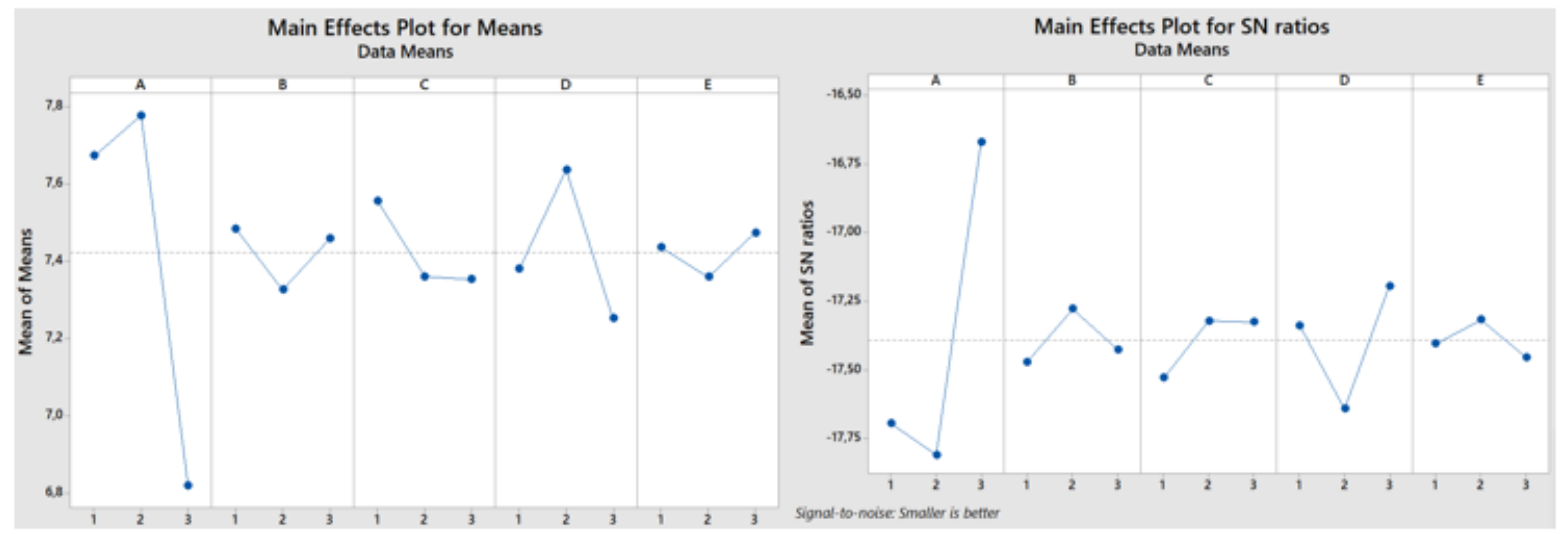

Figure 4 Main Effect for Means and SN ratio Ra 1 result 
Table 4. Surface roughness 2 result

\begin{tabular}{lccccc}
\hline \multirow{2}{*}{ Control factor } & \multicolumn{5}{c}{ Surface roughness Ra 2 } \\
\cline { 2 - 6 } & Level 1 & Level 2 & Level 3 & Delta & Rank \\
\hline & \multicolumn{2}{c}{ S/N } & ratio (dB) & 1 \\
\hline (A) Type of Material & $-17,95$ & $-18,07$ & $-16,93$ & 1,14 & 4 \\
(B) Spindle Speed & $-17,73$ & $-17,53$ & $-17,68$ & 0,19 & 3 \\
(C) Step over & $-17,78$ & $-17,58$ & $-17,58$ & 0,21 & 2 \\
(D) Feedrate & $-17,59$ & $-17,9$ & $-17,45$ & 0,45 & 5 \\
(E) Toolpath & $-17,66$ & $-17,57$ & $-17,71$ & 0,14 & 1 \\
\hline & & \multicolumn{5}{c}{ Means (mm) } & 4 \\
(A) Type of Material & 7,903 & 8,010 & 7,025 & 0,986 \\
(B) Spindle Speed & 7,709 & 7,546 & 7,683 & 0,163 \\
(C) Step over & 7,782 & 7,582 & 7,574 & 0,208 \\
(D) Feedrate & 7,602 & 7,866 & 7,470 & 0,396 \\
(E) Toolpath & 7,659 & 7,581 & 5,698 & 0,118 & 2 \\
\hline
\end{tabular}

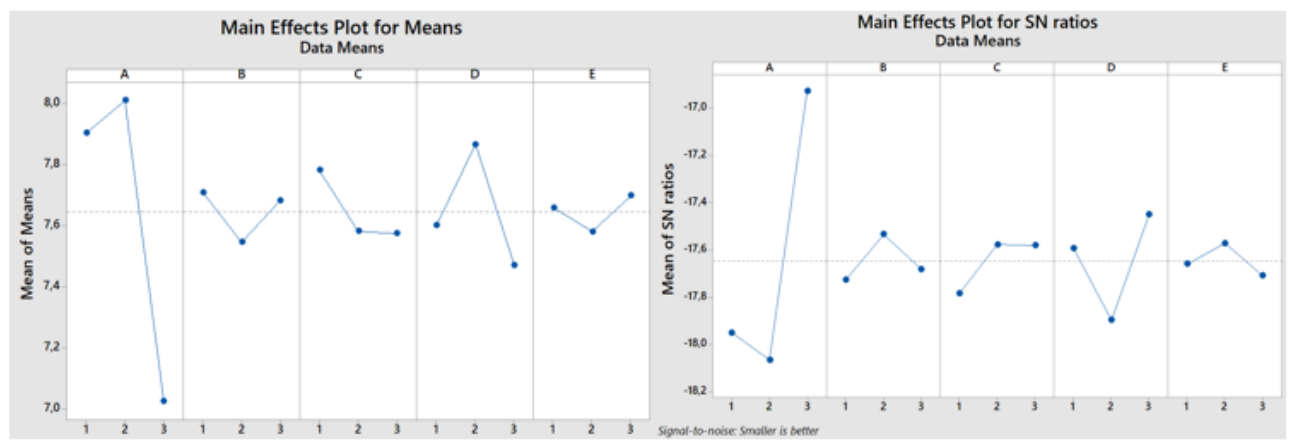

Figure 5 Main Effect for Means and SN ratio Ra 2 result

Table 5. Time machine 1 result

\begin{tabular}{|c|c|c|c|c|c|c|}
\hline & \multirow{2}{*}{ Control factor } & \multicolumn{5}{|c|}{ Surface roughness Ta 1} \\
\hline & & Level 1 & Level 2 & Level 3 & Delta & Rank \\
\hline \multicolumn{7}{|c|}{$\mathrm{S} / \mathrm{N}$ ratio (dB) } \\
\hline (A) & Type of Material & $-50,21$ & $-51,71$ & $-51,83$ & 1,62 & 2 \\
\hline (B) & Spindle Speed & $-51,32$ & $-51,36$ & $-51,07$ & 0,29 & 3 \\
\hline (C) & Step over & $-51,36$ & $-51,07$ & $-51,32$ & 0,29 & 4 \\
\hline (D) & Feedrate & $-51,07$ & $-51,33$ & $-51,35$ & 0,28 & 5 \\
\hline$(\mathrm{E})$ & Toolpath & $-52,68$ & $-50,96$ & $-50,10$ & 2,58 & 1 \\
\hline \multicolumn{7}{|c|}{ Means $(\mu \mathrm{m})$} \\
\hline (A) & Type of Material & 329,9 & 388,0 & 392,6 & 62,7 & 2 \\
\hline (B) & Spindle Speed & 372,8 & 376,2 & 361,3 & 14,9 & 3 \\
\hline (C) & Step over & 376,0 & 362,6 & 371,8 & 13,5 & 4 \\
\hline (D) & Feedrate & 362,4 & 373,7 & 374,3 & 12,0 & 5 \\
\hline$(\mathrm{E})$ & Toolpath & 431,5 & 355,1 & 323,8 & 107,7 & 1 \\
\hline
\end{tabular}

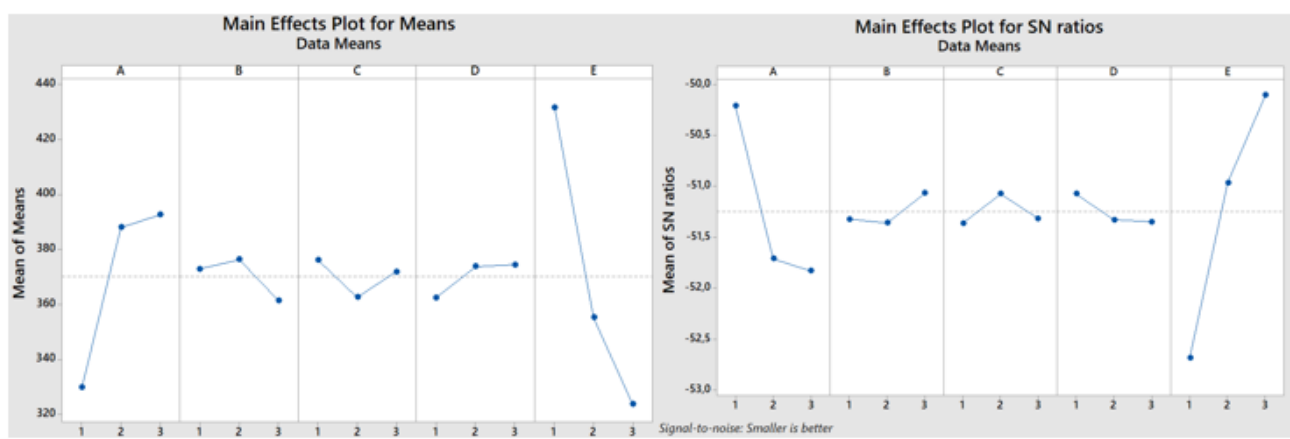

Figure 6 Main Effect for Means and SN ratio TM 1 result 
Table 6. Time machine 2 result

\begin{tabular}{llcccc}
\hline \multirow{2}{*}{ Control factor } & \multicolumn{5}{c}{ Surface roughness Ta 2 } \\
\cline { 2 - 6 } & Level 1 & Level 2 & Level 3 & Delta & Rank \\
\hline & \multicolumn{3}{c}{ S/N } & ratio (dB) & \\
\hline (A) Type of Material & $-50,34$ & $-51,84$ & $-51,96$ & 1,62 & 2 \\
(B) Spindle Speed & $-51,45$ & $-51,49$ & $-51,20$ & 0,29 & 3 \\
(C) Step over & $-51,49$ & $-51,20$ & $-51,44$ & 0,29 & 4 \\
(D) Feedrate & $-51,20$ & $-51,46$ & $-51,48$ & 0,28 & 5 \\
(E) Toolpath & $-52,81$ & $-51,09$ & $-50,23$ & 2,58 & 1 \\
\hline & \multicolumn{5}{c}{ Means (pm) } \\
\hline (A) Type of Material & 334,8 & 393,8 & 398,5 & 63,7 \\
(B) Spindle Speed & 378,4 & 381,9 & 366,7 & 15,1 & 3 \\
(C) Step over & 381,7 & 368,0 & 377,4 & 13,7 & 4 \\
(D) Feedrate & 367,8 & 379,3 & 380,0 & 12,2 & 5 \\
(E) Toolpath & 438,0 & 360,5 & 328,6 & 109,4 & 1 \\
\hline
\end{tabular}

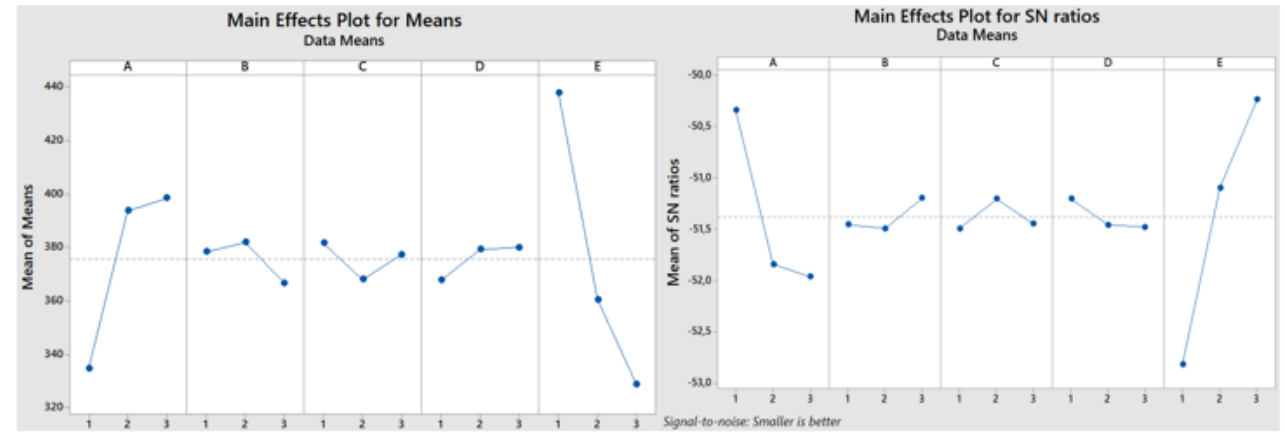

Figure 7 Main Effect for Means and SN ratio TM 2 result

\section{RESULT AND DISCUSSION}

Successful design experiments [2, 3, 4, 6, 7, 21, 22] were continued by researchers to establish a significant link between new EVA foam rubber materials to the measured response. If in previous research $[2,3,4,6,7$, 21, 22, 23] always used one type of EVA foam rubber material with different material hardness values, then in this paper two new types of materials are used. The material was given variable $\mathrm{X}$ and $\mathrm{Y}$ (Table 1 and Figure 3).

Material $\mathrm{X}$ and $\mathrm{Y}$ is a type of EVA rubber foam material that has good machinability properties. Based on the test results using Shore Hardness Tester Asker CL 150 , the hardness of this material ranges from $60-70$ HRC. This material is suitable for health products such as orthopedic shoes, insole, exercise match, and orthopedic support as conveyed by PT. Jakarta Rehabilitation Center.

The orthotic shoe insole design used in this experiment is the optimal design type obtained by previous researchers and used as a research object. This design process is obtained from the CBS-modeling method of previous research $[6,22]$ in figures 2 and 3 . The results of this method can also be applied very well in patients with other foot deformities such as clubfoot [24].
The insole manufacturing process in this paper uses CNC machines with Rolland MDX 40R model type and this is also in accordance with the methods that have been done by [2, 3, 4, 7]. Based on Table 2 and Figure 3, insole manufacturing process was carried out 27 times, while the response value in Table 2, obtained from the average value of surface roughness obtained by researchers from three measurements using Mark Surf PS1 measuring instrument. In order to obtain optimal cutting parameter conditions, the approach using taguchi method is used in this paper. This method is chosen because it can reduce the amount of insignificant treatment and can produce a response value that actually significantly affects the measured response. The quality characteristic of "smaller the better' was chosen by the author's because the quality of the results in this paper is an insole with a surface roughness of less than $10 \mu \mathrm{m}$ and a maximum working time of 6 hours for each desired treatment.

\section{CONCLUSION}

The optimum cutting conditions that approach surface roughness TM shows optimum insole Ra value is $7,431 \mu \mathrm{m}$ (left foot) and 7,654 $\mu \mathrm{m}$ (right foot). Optimal combination of control parameters can be set at the position : spindle speed $=14,000-15.000 \mathrm{rpm}$, stepover $=0,25 \mathrm{~mm}$, federate $=850-900 \mathrm{~mm} / \mathrm{min}$, toolpath $=$ raster900 
The research results show that the use of new materials has a significant effect on the measured response, so that it can be used as a new material for orthotic shoe insoles for patients with bent feet.

In future research, the results of this study can be used as a laboratory or orthotic industry for patients with other foot deformities: club foot, flat feet, pronation, etc.

\section{ACKNOWLEDGMENT}

This research can be completed properly and funded by Direktorat Riset dan Pengabdian Masyarakat, Direktorat Jendral Penguatan Riset dan Pengembangan, Kementrian Riset Teknologi dan Pendidikan Tinggi Republik Indonesia Tahun 2020 No. 25793/UN7.6.1/PP/2020 dan No. 257- 73/UN7.6.1/PP/2020.

Thank you to Mrs Agnes Siti Saliwatun; Mr Andreas as managing director of CV Sibad Engineering Semarang and Mrs. Ririn Diar Astuti, D.Eng as Chief of the Department of Industrial Engineering, Atma Jaya Yogyakarta University who has supported the orthotic research collaboration activities of UNDIP - UAJY.

\section{REFERENCES}

[1] T.X. Qiu, E.C. Teo, Y.B. Yan, and W. Lei, "Finite element modeling of a 3D coupled foot-boot model," Medical Engineering and Physics, 33 (10), 1228-1233, 2011.

[2] P.W. Anggoro, A.A. Anthony, B. Bawono, J. Jamari, A. P. Bayuseno, M. Tauviqirrahman, and A. Nugroho, "CNC milling of EVA foam with varying hardness for custom orthotic shoe insoles and process parameter optimization," Journal of Mechanical Engineering and Sciences," Volume 13, Issue 3, pp. 5347-5370. 2019

[3] P.W. Anggoro, B. Bawono, M. Tauviqirrahman, J. Jamari, A.P. Bayuseno, "Design and manufacturing orthotics shoe insole with optimum surface roughness using the cnc milling," Journal of Engineering Science and Technology," 14(issue 4) 1799 - 1819. 2019

[4] P.W. Anggoro, B. Bawono, M. Tauviqirrahman, J. Jamari, A.P. Bayuseno, Wicaksono, A. "Reverse innovative design of insole shoe orthotic for diabetic patients," Journal of Engineering and Applied Sciences. 14(1) (2019a) 106-113.

[5] E.T. Nurit, W. Ety, H.F. Yifat, and G. Amit, "Role of EVA viscoelastic properties in the protective performance of a sport shoe: computational studies," Journal Bio-Medical \& Material Engineering, vol. 16, pp. 289-299, 2006.

[6] P. W. Anggoro, B. Bawono, A.A. Anthony, J. Jamari, A.P. Bayuseno. "Determining optimal
Toolpath Strategy in the manufacture of orthotic insole shoe made from EVA rubber for diabetes patients." Journal ASL. Paper accepted with code: IJCST 59. 2017

[7] P.W. Anggoro, M. Tauviqirrahman, Jamari, A.P. Bayuseno, B. Bawono, and M.M. Avellina, "Computer-aided reverse engineering system in the design and production of orthotic insole shoes for patients with diabetes," Cogent Engineering, vol. 5, no. 1, pp. 1-20, 2018

[8] L. Uccioli, C. Giacomozzi, "The Role of Footwear in the Prevention of Diabetic Foot Problems," The Diabetic Foot: Medical and Surgical Management, Contemporary Diabetes, Doi: 10.1007/978-161779-791-026, @Springer Science+Business Media. 2012.

[9] P. O. Mogeni, V. A. P. Duraijajah, S. Gobee, "Design and development of a CAD/ CAM system for foot orthoses," The Second International Conference on Technological Advances in Electrical, Electronics and Computer Engineering (TAEECE 2014) Delchambre. 2014.

[10] M. Aloufi, and T. J. Kazmierski, "A response surface modelling approach to performance optimisation of kinetic energy harvesters," International Journal of Research and Reviews in Computer Science, 1-8. 2011.

[11] I. Asiltürk, and S. Neseli, "Multi-response optimization of CNC turning parameters via taguchi method-based response surface analysis," Measurement, vol. 45, pp. 785-794, 2012

[12] S. S. Mahapatra, A. Patnaik, "Study on mechanical and erosion wear behavior of hybrid composites using Taguchi experimental design," Mater. Des, 30, 2791-2801. 2006.

[13] Montgomery, D.C. Design Analysis of Experiments, 8th ed. John Wiley \& Sons, New York, USA, 2013.

[14] M. Thakur Paramjit, R. Rajesh. "Optimal Selection of process parameters in $\mathrm{CNC}$ end milling of $\mathrm{Al}$ 7075-T6 aluminum alloy using a Taguchi approach". Procedia Materials Science, 5 pp 2493 2502. 2014

[15] Ramanujam Radhakrishna, Venkatesan K., Cutting Parameters in Dry Turning on Materials Science. $12 ; 5: 2550.2014$

[16] R. Noorani, Y. Farooque, T. Ioi. 'Improving Surface Roughness of CNC Milling Machined Aluminum Samples Due to Process Parameter Variation". 2009 
[17] Y.R. Jeng, S. Liu, and H-T. Yau, "Designing experimental methods to predict the expansion ratio of EVA foam material and using finite element simulation to estimate the shoe expansion shape," Material Transactions, vol. 53, no. 9, pp. 16851688, 2012.

[18] M.R. Soleymani Yazdi, A. Khorram, "Modeling and Optimization of Milling Process by using RSM and ANN Methods," IACSIT International Journal of Engineering and Technology, Vol.2 No.5, ISSN: 1793-8236. 2010

[19] J. S. Pang, M. N. M. Ansari, S. Omar, Moaz H. Zaroog, Ali, S. M. Sapuan, "Taguchi design optimization of machining parameters on the CNC end milling process of halloysite nanotube with aluminium reinforced epoxy matrix (HNT/Al/Ep) hybrid composite," HBRC Journal, 10, 138-144. 2014.

[20] M. Sarikaya, and A. Gullu, "Taguchi design and response surface methodology-based analyses of machining parameters in CNC turning under MQL," Journal of Clean Production, vol. 65, pp. 604-616, 2014.
[21] P.W. Anggoro, B. Bawono, A. Wijayanto, J. Jamari, A. P. Bayuseno, "Parameter optimatizion of strategies at CNC milling machines Rolland Modela MDX 40R CAM against surface roughness made insole shoe orthotic EVA rubber foam," Int J Mechatronic Mech Eng. 06(4), 96-104. 2016.

[22] B. Bawono, P.W. Anggoro, J. Wibowo, J. Jamari, A.P. Bayuseno. "Optimization Parameters Manufacturing Process of the Product ankle foot orthosis (AFO) for Patients with High Risk Classes." Journal ASL. Paper accepted with code: IJCST 60. 2017

[23] P. W. Anggoro, A. A. Anthony, M. Tauviqirrahman, Jamari, A. P. Bayuseno, Aylie Han. "Machining Parameter Optimization of EVA Foam Orthotic Shoe Insoles," International Journal of Engineering and Technology Innovation, vol. 10, no. 3, 2020, pp. 179-190. 2020

[24] A. A. Anthony, P. W. Anggoro, T. Yuniarto, B. Bawono, A. P. Bayuseno, J. Jamari, ”Semi Reverse Innovative Design of Insole Shoes Orthotic for Patient with Club Foot," Institute of Electrical and Electronics Engineers (IEEE). 978-1-7281-33393/19/\$31.00 @2019 IEEE. 2019 